\title{
La lactancia exclusiva se asocia a una disminución de los síntomas respiratorios en la infancia
}

Relation of infant diet to childhood health: seven year folow up of cohort of children in Dundee infant feeding study. Wilson A, Stewart Forsyth J, Greene S, et al. BMJ 1998;316:21-5

\section{Objetivo}

Investigar la relación entre la alimentación infantil, las enfermedades respiratorias, el crecimiento, la composición corporaly la presión arterial.

\section{Diseño}

Estudio de una cohorte prospectiva.

\section{Lugar}

Muestra poblacional del Hospital General de Dundee. Gran Bretaña.

\section{Participantes}

Cohorte de 545 niños seguidas desde el nacimiento hasta los 7,3 años $(6,1$ a 9,9$)$.

\section{Evaluación de las variables de estudio}

Cuestionario contestado por los padres y revisado en una visita domiciliaria con datos acerca de la duración y edad de comienzo de la lactancia, del uso de fórmula y de semisólidos, síntomas, diagnósticos y tratamientos de enfermedades respiratorias en los últimos 12 meses, historia propia o familiar de atopía, nivel socioeconómico y presencia de fumadores en el hogar.

\section{Mediciones realizadas}

Peso, altura, tensión arterial (TA), pliegue e impedancia bioeléctrica en los pacientes, y altura de los padres.

\section{Resultados principales}

Se completaron los cuestionarios en el $81 \%$ de la muestra, el pliegue tricipital en el $60 \%$, la bioimpedancia en el 59\%, el IMC (índice de masa corporal) en el $61 \%$ y la TA en el $45 \%$. Luego de un ajuste multivariado se reportan solo las variables asociadas significativamente con el patrón alimentario.
Riesgo de síntomas respiratorios según patrón alimentario (\% $\%$ IC 95)

\begin{tabular}{lcccc}
\hline $\begin{array}{l}\text { Primeras 15 } \\
\text { semanas de vida }\end{array}$ & Sibilancias & $\begin{array}{l}\text { Enfermedad } \\
\text { respiratoria (1) }\end{array}$ & Asma (2) & $\begin{array}{c}\text { Tensión } \\
\text { sistólica (3) }\end{array}$ \\
\hline $\begin{array}{l}\text { Pecho exclusivo } \\
(n=141)\end{array}$ & $12,8 \%$ & $17 \%$ & $12,1 \%$ & $90,3 \%$ \\
\hline $\begin{array}{l}\text { Pecho no exclusivo } \\
(n=203)\end{array}$ & $21,3 \%$ & $31 \%$ & $21,7 \%$ & $90,9 \%$ \\
$(16,2-26,1)$ & $(26,8-35,2)$ & $(17,3-26,1)$ & $(90,2-91,6)$ \\
\hline $\begin{array}{l}\text { Biberón exclusivo } \\
(n=201)\end{array}$ & $18,6 \%$ & $32,2 \%$ & $18,6 \%$ & $94,2 \%$ \\
\hline $\begin{array}{l}\text { Sin inclusión } \\
\text { de sólidos }\end{array}$ & $(17,0-21,1)$ & $(30,7-33,7)$ & $(17,2-20)$ & $(93,5-94,9)$ \\
\hline $\begin{array}{l}\text { Con inclusión } \\
\text { de sólidos }\end{array}$ & $(8,6-10,8)$ & & & \\
\hline
\end{tabular}

(1) Tos persistente, sibilancias o disnea

(2) Si fue diagnosticado por algún médico o recibía broncodilatadores

(3) Sólo fue tomada en el $45 \%$ de los pacientes de similares características demográficas al resto de la muestra.

(2) y (3) También se analizaron usando a la duración de la lactancia como variable continúa observándose un efecto dosis-respuesta.

Los pacientes que comienzaron a recibir semisólidos antes de la decimoquinta semana tuvieron un porcentaje de grasa corporal del $18,5 \%$ (IC95\% 18,2-18,8) mientras que los que los recibieron luego fue del $16,5 \%$ (IC95\% 16-17).

\section{Conclusiones}

La lactancia exclusiva se asocia a una reducción significativa de las enfermedades respiratorias en niños, mientras que la introducción temprana de sólidos se asocia con un incremento de la grasa corporal. El uso exclusivo de biberón se asocia a un incremento de la tensión sistólica.

Fuente de financiamiento: Scottish Home and Health Department.

\section{COMENTARIO}

Las guías actuales recomiendan la lactancia exclusiva hasta por lo menos el cuarto mes de vida. Si bien uno debe ser cauto en cuanto a establecer causalidad en este tipo de estudio, el hecho de haber fuerte asociación y en algunas variables también efecto dosis respuesta, brinda mayor fuerza a las conclusiones de este trabajo. Respecto de la TA, es de destacar que sólo fue tomada en el $45 \%$ de los participantes, y no es clara la relevancia clínica de la diferencia observada entre los grupos. El hecho de que la salud del adulto esté determinado por la nutrición recibida en la infancia ha sido motivo de mucho debate desde que Barker en 1993 observó que el bajo peso al nacer y el peso al año de vida están asociados con enfermedades vasculares del adulto (1). Si bien siempre hubo una fuerte recomendación pediátrica con respecto a la lactancia materna, ésta se vio disminuida con el auge de las leches artificiales y volvió a recobrar el impulso a nivel mundial con la aparición en 1981del Código Internacional de Comercialización de Sucedáneos de la Leche Materna aprobado por la asamblea Mundial de la Salud que regulaba la utilización de las mismas (2), y más recientemente en 1991 con la iniciativa "Hospital Amigo de la Madre y el Niño" de la OMS/UNICEF que recomienda absolutamente la làctancia materna hasta los seis meses de vida (3).

Estudios anteriores a éste habían demostrado la reducción de la incidencia de las gastroenteritis y de las enfermedades respiratorias durante los

primeros meses de vida en los pacientes alimentados con lactancia materna exclusiva (4), pero no se había demostrado hasta este trabajo su relación directa hasta la edad preescolar y escolar. Este estudio demostró que la lactancia materna exclusiva hasta por lo menos los primeros cuatro meses se asocia a una significativa reducción de las enfermedades respiratorias durante los primeros años de la vida y que la introducción temprana de los semisólidos se asocia a un incremento estadísticamente significativo de la grasa corporal (no queda claro si una diferencia de un $2 \%$ es clínicamente relevante). Una encuesta de prevalencia de lactancia materna realizada en Argentina sobre una muestra de 417 niños en 1995 reveló que sólo un 42,5\% es alimentado con pecho exclusivo durante el primer mes de vida (5), mientras que la encuesta colaborativa realizada en Argentina por la Subcomisión de Leche Materna de la Sociedad Argentina de Pediatría (6) informó que a los cinco meses de edad sólo un 30\% continúa recibiendo lactancia exclusiva.

Si bién sabemos que nuestra situación socioeconómica impide a muchas madres alimentar a sus hijos con lactancia exclusiva durante los primeros meses, es importante que los médicos estimulemos dicha práctica con el tacto adecuado que la realidad obliga para no generar culpas en quienes no puedan hacerlo.

\section{Dr. Pascual Barán}

Unidad de Medicina Familiar y Preventiva. Hospital Italiano de Buenos Aires.

\section{Dr. Sergio Terrasa}

Unidad de Medicina Familiary Preventiva. Hospital Italiano de Buenos Aires.

\section{Referencias}

1. Barker D, Gluck P, Godfrey K et al. Fetal nutrition and cardiovascular disease in adult life. Lancet 1993:341:938-41.

2. Gutierrez Leyton M. Vigilancia del Código de Comercialización. Una responsabilidad ética ineludible de los pediatras. Arch Arg de Pediatr. 1984;84;34-37.

3. Boletín Informático de la UNICEFF. Año 4, No2, nov 1997.

4. Howie P, Forsyth J, Ogston S, et al. Protective effectof breast feeding against infection. BMJ 1990;300:11-6.

5. Informe sobre la Encuesta de Prevalencia de Lactancia Materna Arch Arg Ped 1998 vol 9650 No1:50-51

6. Ageitos M. Lactancia Materna. En Programa Nacional de Actualización Pediátrica (PRONAP). 1995 Módulo 3, 43-64. 


\section{La vacuna antigripal nasal es segura y efectiva en niños sanos}

The efficacy of live attenuated, cold-adapted, trivalent, intranasal influenzavirus vaccine in children. Belshe RB, Mendelman PM, Tranor J, et al. N Engl J Med 1998; 338:1405-12.

\section{Objetivo}

Determinar la eficacia de la vacuna antigripal a virus atenuados en niños, administrada por vía nasal.

\section{Diseño}

Estudio prospectivo, randomizado, doble ciego y controlado con placebo. Multicéntrico.

\section{Lugar}

EE.UU.

\section{Pacientes}

Niños sanos de 15 a 71 meses (media 42) sin alergia al huevo ni enfermedades crónicas subyacentes.

\section{Intervención}

Se asignaron para recibir 1 dosis 288 niños y para recibir 2 , separadas por 60 días, 1314 niños. La vacuna era antigénicamente equivalente con la inactivada de uso en ese tiempo. Los casos (enfermedad respiratoria, fiebre, vómitos, malestar, irritabilidad o mialgias + cultivo del virus de la influenza en las secreciones respiratorias) se monitorearon durante la estación de gripe subsecuente. Se efectuó un subestudio de respuesta inmunitaria con 203 niños.

\section{Medición de resultados principales}

Eficacia: $1^{\text {er }}$ episodio de gripe confirmada por cultivo para niños que enfermaban luego de 27 días de la $1^{\text {ra }}$ dosis de vacuna o placebo, o en cualquier momento luego de la $2^{\text {da }}$ dosis.

\section{Resultados Principales}

El $18 \%$ del grupo placebo tuvo gripe (cultivo +). De éstos, más del $80 \%$ fueron con fiebre y más de $20 \%$ desarrollaron otitis media. La vacuna antigripal nasal fue aceptada y bien tolerada. Los efectos adversos fueron leves: rinorrea o congestión nasal (Riesgo Relativo [RR] 1.2 ; IC 95\% 1.1-1.4, p< 0.001); fiebre (RR 1.4; IC 95\% 1.0-1.8; p 0.05) y menor actividad (RR $1.3 ; 1.0-1.7 ; \mathrm{p} 0.06)$; y aparecieron después de la primera dosis pero no tras la segunda. Luego de 2 dosis los títulos aumentaban $\geq 4$ veces en $61 \%$ de los niños inicialmente seronegativos para la cepa $\mathrm{A}(\mathrm{H} 1 \mathrm{~N} 1)$ y en $96 \%$ para las cepas $\mathrm{A}(\mathrm{H} 3 \mathrm{~N} 2)$ y $\mathrm{B}$. La segunda dosis fue más importante para la cepa A(H1N1) que para las otras que tenían títulos aceptables con una dosis. Los cultivos positivos de influenza fueron significativamente menos comunes en vacunados (14/1070 niños) que en el grupo placebo (95/532). La eficacia de la vacuna fue del $93 \%$ (IC 95\% 88-96\%); $89 \%$ en el régimen de 1 dosis y $94 \%$ en el de 2 . La vacuna fue eficaz contra las dos cepas $\mathrm{A}(\mathrm{H} 3 \mathrm{~N} 2)$ y $\mathrm{B}$, circulantes en la estación de gripe 1996-1997. Los vacunados redujeron significativamente las enfermedades febriles y un 30\% las otitis medias febriles (IC 95\% 18-45\%; $p<0.001$, número necesario para vacunar: 17) hubo una reducción del uso de antibióticos en estos cuadros de 29 y $35 \%$ respectivamente. La eficacia de la vacuna fue alta tanto para niños menores como para los mayores. Tener un hermano vacunado no fue protector para quienes recibieron placebo.

\section{Conclusiones}

La vacuna fue segura, inmunogénica y efectiva en niños sanos contra las dos cepas circulantes en la estación de gripe del estudio.

\section{COMENTARIO}

La gripe continúa siendo una importante causa de morbimortalidad a pesar de la recomendación de vacunar a personas de alto riesgo $<65$ años y a los $\geq 65$ años. La inmunización de estos grupos es costo-efectiva y reduce las complicaciones serias de la gripe (1), pero es francamente subutilizada especialmente en pacientes de alto riesgo y más aún a edades menores (2)(3). Las barreras más importantes son el temor a efectos adversos, la aplicación anual, la percepción de una baja eficacia y, para niños $<9$ años, la necesidad de dos inyecciones. La administración nasal podría aumentar la aceptabilidad de padres e hijos y potencialmente mejorar la inmunogenicidad al estimular las Ig A secretorias además de las Ig $\mathrm{G}$, pero sería necesario evaluar la eficacia de la vacuna en una estación en que la cepa $A(H 1 N 1)$, de menor inmunogenicidad, esté circulando. ¿Debería diseminarse la vacunación antigripal infantil como proponen los autores?

La antigripal nasal es eficaz y de fácil administración. Si bien no fue comparada con la inactivada los datos históricos de ésta (eficacia
$70-90 \%$ (3) y otros estudios (4) sugieren que la vacuna a virus atenuados es tan o más eficaz que la inactivada.

Parecería conveniente diseminar la vacunación entre niños de alto riesgo pues al evitar la doble inyección se lograría mejor cobertura e impacto preventivo. La inmunización infantil universal es menos clara. Si bien los niños son una fuente de transmisión de gripe en la comunidad, es improbable que la prevención en este grupo $(<10 \%$ de complicaciones serias) sea suficiente para disminuir la morbilidad global. Además, este estudio no halló que la incidencia de gripe disminuya entre los convivientes de los vacunados por lo que también sería necesaria una amplia cobertura en adultos sanos y de riesgo para disminuir la gripe en la comunidad. La vacuna antigripal nasal es una buena noticia para pacientes de riesgo (niños y adultos), niños con alto riesgo de otitis media o de exposición al virus como en guarderías; pero sería prematuro plantearse la extensión de las recomendaciones actuales sin serios estudios previos de costo-efectividad.

*Ver Glosario

\section{Dr. Agustín Ciapponi}

